\title{
Os impactos da regulação ambiental na inovação: algumas considerações
}

\author{
Thierry Prates* \\ Maurício Serra ${ }^{* *}$
}

As inovações ambientais diferem fundamentalmente de outros tipos de inovação, principalmente devido aos estímulos a que respondem. As tecnologias ambientais, ao contrário das outras tecnologias, possuem funções sociais e não têm a função prioritária de melhorar os resultados comerciais da empresa (embora possam desempenhar essa função).

Um aspecto importante no que tange a inovação é o fato de que ela, segundo a vasta literatura a respeito dos clusters, se torna mais freqüente quando há cooperação entre os agentes. Na maior parte dos casos, promover a cooperação entre os atores é a tarefa mais difícil para os formuladores de políticas públicas. A proximidade entre as firmas pode proporcionar um ambiente de confiança, troca de informações e ação conjunta. Em certos momentos a cooperação entre os produtores pode ocorrer se o setor enfrenta uma crise, que pode ser derivada de uma maior pressão regulatória dos órgãos ambientais. Os países em que a regulação ambiental foi aplicada cedo e com rigor, foram aqueles que progrediram mais no processo de inovação, antecipando assim seus lucros e preenchendo um vazio existente na oferta, podendo então cobrar altos preços num mercado onde a competição não é muito acirrada e auferir lucros extraordinários (Barton, 1998).

As empresas que desenvolvem tecnologias ambientais não obedecem rigorosamente aos mesmos estímulos de mercado. Um outro conjunto de fatores determina o processo desse tipo de inovação, entre eles o mais importante é o marco regulatório. A despeito do papel central da regulação, a inovação ambiental não pode ser considerada apenas uma resposta a este estímulo específico. Existem vários outros fatores que governam a inovação ambiental. Os determinantes da inovação ambiental segundo Kemp et al (2000) foram reunidos em três grupos, a saber:

- Os incentivos a inovar dependem da intensidade da competição, das condições de custos e demanda (por exemplo, os custos de disposição de resíduos, preços de energia, demanda por produtos ambientalmente corretos, menores taxas de seguro para empresas

\footnotetext{
* Doutor em Desenvolvimento Econômico pelo Programa de Pós-Graduação em Desenvolvimento Econômico da Universidade Federal do Paraná (PPGDE/UFPR). Professor da Universidade Estadual de Ponta Grossa (UEPG). E-mail: thierry prates@hotmail.com

** Doutor pela London School of Economics (LSE). Professor do Departamento de Economia e do Programa de Pós-Graduação em Desenvolvimento Econômico da Universidade Federal do Paraná (PPGDE/UFPR). Email : serra@ufpr.br
} 
ambientalmente corretas), e das condições de apropriabilidade (até que ponto uma inovação é capaz de capturar os benefícios econômicos de sua inovação).

- A habilidade de assimilar e combinar conhecimento de diferentes fontes (dentro e fora da firma), que é necessária para produzir novos produtos e processos (conhecimento tecnológico e conhecimento do mercado).

- A capacidade de gerenciar o processo de inovação: forma especial de gestão. Gestão da atenção, gestão das idéias, gestão dos relacionamentos entre as partes, isto é, integração de funções, unidades e recursos.

Desde que entrou em pauta, nos anos sessenta, a questão das tecnologias ambientais sempre foi alvo de discussões e controvérsias. Por um lado, a necessidade de limpar a produção para que a vida na Terra continuasse viável e por outro, o impacto nos custos gerados pela introdução dessas novas tecnologias. No decorrer das últimas décadas o peso variou entre esses dois lados, mas a partir dos anos noventa as tecnologias limpas se consolidaram como uma solução necessária e mais viável. Em geral, o resultado da comparação custo-benefício no controle da poluição é negativo, portanto, não se considera como uma prioridade para as firmas e nem se espera que se movam por si só (Kemp \& Soete, 1990). A intervenção nesses casos onde não haja estímulos de mercado é fundamental, e ela surge a partir das necessidades populares. A regulação é uma resposta institucionalizada à demanda pública por proteção ambiental (Kemp et al, 2000). Na realidade, a regulação é vista como a mãe das inovações sociais, mas para as inovações normais é o oposto, um fator inibidor para as firmas, prevenindo-as de explorar oportunidades tecnológicas (Ashford, 2000). A regulação age como um filtro, ao focar instrumentos de mudança técnica que sejam capazes incentivar as firmas a atingir certos padrões ambientalmente desejáveis (Kemp et al, 2000).

De acordo com Lustosa (2003), os determinantes do investimento ambiental são:

- Regulação ambiental - incentivo para que as firmas se tornem menos agressivas e tomem medidas para reduzir os problemas ambientais;

- Pressão dos consumidores finais e intermediários - aumentou sensivelmente com o aumento da conscientização ambiental, mas ainda revela grandes diferenças entre países ricos e pobres.

- Pressão dos stakeholders - sociedade civil, parlamentares, populações residentes do entorno de uma atividade que gere externalidades negativas ao meio ambiente, ONGS e ambientalistas.

130 
- Pressão dos investidores - risco de passivos financeiros decorrentes de infrações ambientais.

Esses argumentos são fundamentais para associar as mudanças na regulação como um fator decisivo para o estímulo à inovação. Ainda que seja correto afirmar que nos últimos quinze anos uma parte dessa motivação tenha se deslocado para a estratégia das firmas, a regulação ainda desempenha papel central no estímulo á mudança tecnológica no setor ambiental.

De fato, a trajetória da regulação ambiental se confunde com a história do meioambiente e da economia. Skea (2000) identifica três fases na evolução da regulação ambiental: 1) a regulação era, no final dos anos 60 , baseada em ações pró-ativas, geralmente End-of-Pipe, com a finalidade de evitar prejuízos ambientais imediatos; 2) após 1973, a ação dos governos e órgãos ambientais caracterizou-se por fazer um "jogo morto", onde o aumento da regulação ambiental era visto como um entrave ao crescimento da produção e do comércio; e 3) a partir de 1993, fase esta que pode ser considerada como um renascimento da regulação com ênfase na inovação e nas tecnologias limpas (Pollution Prevention).

A classificação das fases de evolução da regulação feita por Skea (2000), combina com a evolução dos principais sistemas regionais de inovação em tecnologias ambientais mundiais, pois os incentivos da regulação variaram em intensidade com o tempo. Por ser uma tecnologia social, o principal incentivo é a regulação e não a motivação por lucros. No entanto, as vantagens em "ser o primeiro", e se apoderar dos benefícios econômicos da inovação, podem ser grandes se o marco regulatório nivelar o comportamento das firmas através de padrões de comportamento ambiental.

De um modo geral, todos os setores industriais merecem atenção em relação aos possíveis problemas causados pela má gestão ambiental. No entanto, alguns setores possuem maior intensidade potencial de emissões, devido ao fato de utilizarem recursos naturais e energia em abundância no processo produtivo.

O Quadro 1 apresenta os setores que mais se destacam em termos de intensidade potencial de emissão e os respectivos poluentes lançados no meio-ambiente. Essas atividades se expandiram por todo o país após a consolidação de investimentos do II PND (Young \& Pereira, 2000; Young \& Lustosa, 2001). 
Quadro 1 - Setores Com Maior Intensidade Potencial de Emissão

\begin{tabular}{|l|l|}
\hline Poluente & Setores industriais \\
\hline Carga orgânica (DBO) & $\begin{array}{l}\text { Metalurgia de não-ferrosos; papel e gráfica; químicos não } \\
\text { petroquímicos; indústria do açúcar. }\end{array}$ \\
\hline Sólidos suspensos (água) & Siderurgia \\
\hline $\mathrm{SO} 2$ & $\begin{array}{l}\text { Metalurgia de não-ferrosos; siderurgia; refino de petróleo e } \\
\text { indústria petroquímica. }\end{array}$ \\
\hline $\mathrm{NO} 2$ & Refino de petróleo e indústria petroquímica; siderurgia. \\
\hline $\mathrm{CO}$ & $\begin{array}{l}\text { Siderurgia; metalurgia de não-ferrosos; químicos diversos; } \\
\text { refino de petróleo e indústria petroquímica. }\end{array}$ \\
\hline $\begin{array}{l}\text { Compostos orgânicos } \\
\text { Voláteis }\end{array}$ & $\begin{array}{l}\text { Refino de petróleo e indústria petroquímica; siderurgia; } \\
\text { químicos diversos. }\end{array}$ \\
\hline Particulados (ar) & $\begin{array}{l}\text { Siderurgia; óleos vegetais e gorduras p/ alimentação; minerais } \\
\text { não-metálicos. }\end{array}$ \\
\hline
\end{tabular}

Fonte: Young e Pereira (2000).

Como se pode notar, a siderurgia e o refino de petróleo estão em quase todas as categorias de poluição. A especialização regional nesta qualidade de indústrias "sujas" pode trazer graves conseqüências para as próprias indústrias, que em um momento posterior podem ser obrigadas a incorrer em altos custos de "limpeza" com o objetivo de se adequarem à legislação ambiental ou para alcançarem mercados mais exigentes.

Por outro lado, a existência de firmas com alto potencial de poluição em um ambiente fortemente regulado, cria a expectativa de que sejam criadoras de soluções ambientais para seus próprios problemas e até fornecedoras de tecnologias ambientais para outros setores (Kemp \& Soete, 1990; Porter \& Linde, 1995). Em geral, essas empresas com maior potencial de poluição, sofrem grande pressão de órgãos fiscalizadores, clientes, investidores, seguradoras e da sociedade civil para que resolvam seus problemas e ofereçam produtos ambientalmente corretos respeitando o meio ambiente durante o processo de produção.

Essa pressão de todos os lados é importante para que a empresa tenha a segurança de que o investimento em tecnologias ambientais será uma garantia de bons negócios. As indústrias incluídas nessas categorias são, em geral, de grande porte devido à própria natureza das atividades, que exige uma escala maior. Empresas menores recebem uma pressão menor. No entanto, em pequenas empresas fornecedoras para as grandes, muitas vezes ocorre pressão dos clientes para que o produto esteja em conformidade com o meio ambiente.

São várias as referências às tecnologias ambientais como instrumento de redução de custos e competitividade, não podem ser consideradas como regras gerais, no entanto. $\mathrm{O}$ argumento mais conhecido é chamado de hipótese de Porter, segundo a qual as empresas respondem à regulação através das inovações, e que esse comportamento pode ser benéfico 
para a própria firma (Porter \& Linde, 1995a; 1995b; Porter, 1990). Os trabalhos relatam a importância da regulação ambiental no estímulo à inovação e na criação de mercados para produtos ambientais, assim como várias histórias de sucesso de empresas que implantaram processos limpos e reduziram custos.

Segundo Porter (1996), o conflito entre proteção ambiental e competitividade econômica é uma falsa dicotomia. As análises citadas, principalmente a de Porter e Linde (1995a), demonstram que as empresas internacionais competitivas são mais capazes de inovar, em resposta a um estímulo regulatório. A hipótese de Porter está no centro da discussão sobre a influência da regulação no estímulo à inovação ambiental. Muitos problemas ligados à inovação ambiental no estado do Paraná estão relacionados diretamente com a influência da regulação e da fiscalização, e podem ser explicados parcialmente pela hipótese de Porter. Por outro lado, a realidade mostra que não há apenas histórias de sucesso, ou uma saída simples para todas as firmas. Os exemplos de Porter e Linde (1995a) são sucessos na solução de problemas ambientais e redução nos custos, contudo, não representam firmas de todos os tamanhos e setores, não mostram as diferenças entre empresas que utilizam distintas quantidades de recursos naturais e nem mesmo aquelas que são atingidas com mais rigor pela regulação. Os autores admitem que os seus exemplos não provam que as firmas podem sempre inovar para reduzir o impacto ambiental a um baixo custo, mas eles mostram que existem oportunidades consideráveis para reduzir a poluição através de inovações que redesenham produtos, processos e métodos de operação (Porter \& Linde 1995b).

A classificação de Skea (2000), apresentada anteriormente, e que identifica três fases na evolução da regulação ambiental, pode ser usada para se fazer um paralelo entre o movimento dos sistemas regionais de inovação ambientais e essa evolução da regulação. Em países onde a regulação se desenvolveu mais rapidamente, como Japão, Estados Unidos e Alemanha, os sistemas nacionais e regionais evoluíram mais rapidamente e se tornaram referência internacional em diversos setores, na maior parte EOP, como limpeza de carvão, energias renováveis e sistemas de purificação de águas residuais.

Mais recentemente, a regulação se tornou mais restritiva e específica. Ao mesmo tempo houve um aumento da compreensão por parte das nações, regiões e das firmas de que o processo de limpeza industrial é irreversível, muitas vezes lucrativo, e de que existe uma vantagem clara em ser o primeiro, o que tornou o mercado de tecnologias ambientais uma fatia desejada por muitas regiões, prontas a organizar planos para explorar as vantagens já existentes e atrair novos investimentos, gerando emprego, renda e desenvolvimento 
econômico. O Quadro 2 mostra a evolução da regulação descrita acima e alguns dos sistemas regionais de inovação ambiental que surgem ao longo desse período.

Quadro 2: Evolução da Regulação e SRIs Ambientais - 1965-2005

\begin{tabular}{|c|c|c|c|}
\hline & Evolução da Regulação & $\begin{array}{l}\text { Evolução dos Sistemas } \\
\text { Ambientais }\end{array}$ & $\begin{array}{l}\text { Regiões/ } \\
\text { período } \\
\text { aproximado }\end{array}$ \\
\hline $\begin{array}{l}1965 \\
a \\
1970\end{array}$ & $\begin{array}{l}\text { No final dos anos } 60 \text { a regulação se } \\
\text { baseava em ações pró-ativas com o } \\
\text { objetivo de evitar prejuízos ao meio } \\
\text { ambiente. A regulação apresenta maior } \\
\text { força após os relatórios do Clube de } \\
\text { Roma e outros modelos relativos ao meio } \\
\text { ambiente e crescimento, principalmente } \\
\text { em países desenvolvidos. }\end{array}$ & $\begin{array}{l}\text { Ações corretivas imediatas (EOP) são } \\
\text { tomadas pelas firmas a fim de atender } \\
\text { às exigências da regulação. Alguns } \\
\text { sistemas começam a surgir. Os sistemas } \\
\text { de inovação ambiental ainda não } \\
\text { existiam de maneira organizada. Alguns } \\
\text { começam a surgir de forma espontânea, } \\
\text { principalmente em setores muito } \\
\text { poluentes afetados pela regulação. }\end{array}$ & EUA (1970) \\
\hline $\begin{array}{l}1973 \\
\mathrm{a} \\
1992\end{array}$ & $\begin{array}{l}\text { Jogo morto - no período de quase } 20 \\
\text { anos, após 1973, a regulação ambiental } \\
\text { perde força no argumento dos custos } \\
\text { econômicos da produção limpa, se } \\
\text { tornando um "empecilho" } \\
\text { crescimento econômico. }\end{array}$ & $\begin{array}{l}\text { Alguns sistemas pioneiros, como os de } \\
\text { Alemanha, Japão e EUA, conseguem } \\
\text { resultados econômicos importantes, se } \\
\text { tornando monopolistas em tecnologias } \\
\text { ambientais EOP. }\end{array}$ & $\begin{array}{l}\text { North-Rhine } \\
\text { W. (1972) } \\
\text { Japão(1973) } \\
\text { Reino Unido } \\
(1990)\end{array}$ \\
\hline 1993 & $\begin{array}{l}\text { Apos a Rio 92, a regulação ganha novo } \\
\text { fôlego, mas com novas metas de } \\
\text { incentivo às tecnologias ambientais e } \\
\text { sistemas limpos. }\end{array}$ & $\begin{array}{l}\text { Os sistemas ambientais apresentam } \\
\text { crescimento em número e em } \\
\text { especialidades, em grande parte devido } \\
\text { aos incentivos regulatórios. }\end{array}$ & Finlândia(1994) \\
\hline 1995 & $\begin{array}{l}\text { Fortalece-se o argumento da produção } \\
\text { limpa como oportunidade econômica, } \\
\text { direcionando a política regional de C\&T } \\
\text { para as questões do meio ambiente e } \\
\text { competitividade das localidades. }\end{array}$ & $\begin{array}{l}\text { Não apenas o incentivo punitivo ou } \\
\text { financeiro, mas também } \\
\text { planejamento das regiões inclui a } \\
\text { formação de sistemas e clusters em } \\
\text { tecnologias ambientais. }\end{array}$ & \\
\hline 2000 & $\begin{array}{l}\text { A regulação, em muitos países, já está } \\
\text { consolidada. As regiões buscam se inserir } \\
\text { neste novo e promissor mercado de } \\
\text { tecnologias ambientais criando incentivos } \\
\text { variados. }\end{array}$ & $\begin{array}{l}\text { Muitos países procuram elaborar planos } \\
\text { de desenvolvimento de clusters e } \\
\text { sistemas regionais de inovação na área } \\
\text { de meio ambiente }\end{array}$ & $\begin{array}{l}\text { Peterborough - } \\
\text { Canadá (2000) }\end{array}$ \\
\hline 2005 & $\begin{array}{l}\text { Os consumidores são conscientes e } \\
\text { informados, e a regulação é cada vez mais } \\
\text { específica e rígida, em virtude do } \\
\text { aumento da complexidade dos problemas } \\
\text { ambientais. }\end{array}$ & $\begin{array}{l}\text { Os mercados internacionais são } \\
\text { exigentes e buscam tecnologias de } \\
\text { fronteira. Ainda há espaço em setores } \\
\text { específicos onde novos SRIs podem } \\
\text { participar, porém o domínio ainda } \\
\text { pertence aos países pioneiros. }\end{array}$ & \\
\hline
\end{tabular}

Fonte: Prates, 2006.

A primeira fase, nos anos 60 , é o início do despertar para as questões ambientais, que ainda são vistas pelo setor produtivo com certo preconceito com respeito aos ecologistas. Uma série de trabalhos surge e cria um ambiente de apreensão no início dos anos 70, estimulando a criação de regulação específica e o aparecimento natural dos primeiros embriões de sistemas de inovação ligados às tecnologias ambientais.

Os altos custos na implantação de tecnologias ambientais, principalmente EOP, reforçam o trade-off entre a produção limpa e os lucros durante aproximadamente vinte anos. 
A regulação, apesar de estar capacitada para resolver a maior parte dos problemas ambientais na indústria faz, nesse período, "vistas grossas" aos infratores, exercendo um papel marginal no incentivo às tecnologias ambientais.

A partir dos anos noventa, a questão ambiental entrou definitivamente na agenda dos países e das indústrias. A retomada da força da regulação e o aumento da percepção a respeito das vantagens econômicas provenientes das soluções ambientais motivaram investimentos e planejamentos para o setor de tecnologias ambientais em diversos países e regiões. De fato, a legislação tem se tornado cada vez mais específica e abrangido não só os recursos hídricos e efluentes, como também os resíduos sólidos e as emissões atmosféricas, com padrões estabelecidos para as emissões. Há também uma comprovada melhoria na atuação dos órgãos ambientais, que antigamente se restringiam somente a orientar as empresas a respeito das melhores tecnologias disponíveis para a queima de combustíveis.

\section{Referências Bibliográficas}

ASHFORD, N. A. (2000), An Innovation-Based Strategy for a Sustainable Environment. In: HEMMELSKAMP, J.; RENNINGS, K. \& LEONE, F., Innovation-Oriented Environmental Regulation: Theoretical Approaches and Empirical Analysis, Heidelberg: Physical Verlag.

KEMP, R. E. \& SOETE, L. (1990), Inside the Green Box: on the economics of technological change and the environment. In: FREEMAN, C. \& SOETE, L. (eds.), New Explorations in the Economics of Technological Change, London: Pinter.

KEMP, R.; SMITH, K. \& BECHER, G. (2000), How we Should Study the Relationship between Environmental Regulation and Innovation?. In: HEMMELSKAMP, J.; RENNINGS, K. \& LEONE, F., Innovation-Oriented Environmental Regulation: Theoretical Approaches and Empirical Analysis, Heidelberg: Physical Verlag.

PORTER, M. (1990), The Competitive Advantage of Nations, London: Macmillan.

PORTER, M. \& VAN DER LINDE, C. (1995a), Toward a New Conception of The Environment-Competitiveness Relationship, Journal of Economic Perspectives, Vol. 9, $\mathrm{n}^{\circ} 4$.

PORTER, M. \& VAN DER LINDE, C. (1995b), Green and Competitive: Ending the Stalemate, Harvard Business Review, 73 (5), pp. 120-134.

PORTER, M. (1996), America's Green Strategy. In: WELFORD, R. \& STANKEY, R., The Earthscan Reader in Business and the Environment.

PRATES, T. M. (2006), Sistemas Regionais de Inovação em Tecnologias Ambientais: Um Estudo de Caso do Paraná, Programa de Pós-Graduação em Desenvolvimento Econômico: UFPR (Tese de Doutorado). 
